\title{
Student Perceptions Towards the use of YouTube as An Educational Tool for Learning and Tutorials
}

\section{Eugine Tafadzwa Maziriri}

Department of Business Management, Faculty of Economic and Management Sciences, University of the Free State, MaziririET@ufs.ac.za

\section{Parson Gapa}

Faculty of Information Technology, Monash University, South Africa, parsgp1@gmail.com

\section{Tinashe Chuchu}

Department of Marketing Management, Faculty of Economic and Management

Sciences, University of Pretoria, tinashe.chuchu@up.ac.za

\begin{abstract}
YouTube as an educational tool has been recently receiving a great deal of attention from researchers and teachers. The study in question therefore investigates this phenomenon. To this end, a modified conceptual model based on the technology acceptance model (TAM) was proposed to test student perceptions, attitudes and intentions to adopt YouTube as an educational tool. The study was quantitative in nature where 377 registered students from a selected university were chosen through non-probability sampling. In order to analyse the data SPSS 25 and AMOS 25 were utilised for descriptive statistics and structural equation modeling respectively. Perceived usefulness of YouTube and perceived ease of use where proposed as antecedents of attitudes and intentions while adoption of YouTube as an educational tool was anticipated to be the outcome. The main findings suggested that perceived usefulness was observed to have a more significant impact on student perceptions toward learning through YouTube in comparison to the perceived ease of use. In addition, it was also discovered that intention to use YouTube and adoption of YouTube as an educational tool had the strongest relationship of all tested hypotheses. Implications for educators and researchers were established from the findings. Thereafter, suggestions for further research were proposed.
\end{abstract}

Keywords: YouTube, education, tool, students, learning, tutorials

Citation: Maziriri, E. T., Gapa, P., \& Chuchu, T. (2020). Student Perceptions Towards the use of YouTube as An Educational Tool for Learning and Tutorials. International Journal of Instruction, 13(2), 119-138. https://doi.org/10.29333/iji.2020.1329a 


\section{INTRODUCTION}

YouTube, founded in 2005, is a video-sharing which is considered to be a relatively new phenomenon, and teachers together with researchers have started to pay close attention to its possibilities within the educational setting. (Mullen \& Wedwick, 2008). In addition, it was suggested by Mullen \& Wedwick (2008) that videos have the potential to enhance almost any classroom lesson and this are available on YouTube and other video sharing web sites such as TeacherTube, SchoolTube, United Streaming, OneWorldTV, Yahoo! Video, Google Video, and MSN Soapbox. YouTube provides free access to a substantial amount of educational videos (Buzzetto-More, 2014) therefore making it a viable option for students to receive useful material for learning purposes. YouTube provides a professional platform through YouTube EDU for learning outside from the informal communication channels. According to BuzzettoMore (2014). YouTube EDU is a service for educators which contains short lessons from teachers, entire university courses, professional development materials, and motivational videos from international leaders. Research on Youtube in the classroom does not necessary shed light on an utterly new phenomena but has been explored in literature (Berk, 2009) who assessed multimedia teaching using YouTube videos.

Despite the availability of YouTube research, it is essential to note that there is still a shortage of empirical evidence of causal relationships between perceived usefulness of YouTube, perceived ease of use of YouTube, student attitudes towards the use of YouTube and Behavioural intention to Use YouTube. Consequently, further scholarly introspections are considered necessary. Much of what is written on the subject is based on samples from developed countries such as Saudi Arabia, Hong Kong, Malaysia and United Kingdom.

For example Almobarraz (2018) determined the utilisation of YouTube as an information resource to support university courses in Saudi Arabia. In addition, Szeto and Cheng (2014) determined the usage of ICT tools and YouTube for teaching during their teaching practicums in Hong Kong. Albahlal (2019) investigated the impact of youtube on improving secondary school students' speaking skills in Riyadh. Furthermore, June, Yaacob and Kheng (2014) investigated the use of YouTube videos and interactive activities in stimulating critical thinking among students from a public university in Malaysia. Duncan, Yarwood-Ross and Haigh (2013) examined YouTube as a source of clinical skills education in United Kingdom.

In addition, previous academics have performed their research in different environments within the South African context, by concentrating on YouTube as an academic tool for ICT lecturers (Roodt, de Villiers, Johnston, Ophoff \& Peier, 2014). Using YouTube in the classroom for the net generation of students (Roodt \& Peier, 2013). In addition, Jordaan and Jordaan (2017) conducted a study which focused on using YouTube as a reflection tool for a service-learning module at the University of Pretoria in South Africa. Moreover, Olasina (2017) conducted an evaluation of educational values of YouTube videos for academic writing among students in Scottsville, Province of KwaZulu-Natal, South Africa. 
Inferring from the aforementioned studies, there is scant evidence of studies focusing on the background that influences on behavioural intentions of students to use YouTube as an educational tool for learning and tutorials. The fundamental motivation behind this investigation is to fill this gap. Very few (if any) researchers have used structural equation modeling (SEM) to test the causal relationships between Perceived usefulness of YouTube Tutorials, Perceived ease of use of YouTube, Student Attitudes towards the use of YouTube and Behavioural intention to Use YouTube. In terms of this study, this robust research model is one of a kind

In light of the research void aforesaid, the focal purpose of the current research is to establish the extent to which technologies such as YouTube were perceived as being effective as learning aids by students. To bridge the research gap, three empirical objectives are put forward, that is:

- To investigate the relationship between perceived usefulness of YouTube Tutorials and student attitudes toward the use of YouTube for Tutorials

- To investigate the relationship between perceived ease of using You Tube Tutorials and student attitudes toward the use of YouTube for Tutorials

- To investigate the relationship between student attitudes toward the use of You Tube Tutorials and behavioural intention to use YouTube

The composition of this paper is structured as follows: first, this research is placed into context and thereafter the problem statement as well as the motivation of the study is highlighted. The literature review will follow, which includes the theoretical, empirical review, conceptual model and hypotheses development. Subsequent to this is the methodology section, then the findings as well as the conclusions and recommendations.

\section{Putting Research into Context: YouTube in Education}

YouTube (www.youtube.com) is the largest online video material repository with more than one billion users (Camm, Russell, Xu \& Rajappan 2018). YouTube's use in the instructional process gives students and teachers benefits (Alkhudaydi, 2018). These benefits include: attracting students attention, focusing students concentration, observing hard-to-observe experiences, generating interest in the subject, improving content attitudes, building a connection with students, fostering creativity, increasing collaboration, motivating students, making learning fun, decreasing anxiety about scary topics, increasing understanding,

YouTube has also been found to be the best fit for digital learners Net Generation characteristics (students raised since the introduction of the World Wide Web) and a valid approach to tapping their multiple intelligences and learning styles (Liu, 2010) with high acceptance levels (Buzzetto-More, 2014; Donoker, 2011; Kelly, Lyng, McGrath, and Cannon, 2009). The use of online and hybrid courses has been found to enhance discourse, collaboration and engagement (Buzzetto-More, 2014; Greenberg \& Zanetis, 2012; Revoir, 2012). Videos can be integrated into most learning management systems and incorporated into courses, assignments, quizzes and tutorials (Snelson, 
2010), as well as used to support independent learning and tutoring (Berk, 2009 as well as Kelly, Lyng, McGrath \& Cannon, 2009). While some studies have found YouTube particularly effective in enhancing full online courses (Jones \& Graham, 2002), others have indicated that the use of online video sharing services is most effective when used to complement rather than replace hybrid or blended model lecturer demonstrations (Kelly, McGrath, \& Cannon, 2009).

In a study by Balcikanli of' L2 Stories on YouTube in Language Learning (2011), the study results concluded that the students took advantage of YouTube to improve their language skills and out - of-class experience, particularly in terms of independence skills and cultural skills. In addition, a study on YouTube, language learning, and teaching techniques was conducted by Alimemaj (2010). The students' data implied that the Internet and YouTube were great potential language learning resources. Furthermore, students had positive ideas about using YouTube for learning their own language. Furthermore, Watkins and Wilkins (2011) studied' Using YouTube in the EFL Classroom' and the study concluded that the ability to speak, listen and pronounce can be enhanced by using YouTube; inside and outside the classroom. In addition, the study also suggested that using YouTube videos as realia would stimulate cultural lessons, expose students to World English, and help promote the development of authentic vocabulary. Research also shows that the outcomes of students are improved by integrating videos into instruction (Alwehaibi, 2015; Jones \& Cuthrell, 2011). Figure 1 below shows a picture of the homepage of YouTube.

\section{Statement of the Problem and Motivation for Research}

Some of the challenges in learning stem from the acknowledgement that there is a lack of communication amongst lecturers (Paras, 2001), which then affects students who are supposed to benefit from all their lecturers. This then give rise to the need for new forms or platforms for leaning that standardise the learning process. This study make the case that YouTube is one of those platforms. YouTube is becoming a prominent platform for students to self-teach and enhance the learning skill for formal assessments in class. However, there is a dearth on literature regarding the extents of its effectiveness especially the impact that tutorials have on student learning. This research therefore aims to make the case for how effective YouTube is in advancing student comprehension of learning concepts. The findings of this study are expected to contribute new knowledge to the existing body of education management, instruction and learning literature.

\section{THEORETICAL GROUNDING}

Theoretical underpinning for the research was grounded in two theories; the theory of planned behaviour and the technology acceptance model (TAM) as these theories would help explain user acceptance of technology such as YouTube with the later (TAM) being empirically tested.

\section{Moreno and Mayer's Cognitive Theory of Multimedia}

Multimedia learning's cognitive theory focuses on the idea that students try to build meaningful connections between words and pictures and learn more deeply than they 
can have with words or pictures alone (Mayer, 2009). One of the principles aimed at multimedia instruction, according to cognitive theory of multimedia learning, is to encourage the student to build a coherent mental representation from the material presented. The job of the student is to make sense as an active participant of the presented material, ultimately building new knowledge. The cognitive theory of multimedia learning is based on three assumptions, according to Mayer and Moreno (1998) and Mayer (2003): the dual-channel assumption, the limited capacity assumption, and the active processing assumption. The assumption of dual-channel is that working memory has auditory and visual channels based on the theory of working memory of Baddeley (1986) and dual coding theory of Paivio (1986; Clark \& Paivio, 1991). Second, the assumption of limited capacity is based on cognitive load theory (Sweller, $1988,1994)$ and states that each working memory subsystem has limited capacity. The third assumption is the active processing assumption that suggests that people build knowledge in meaningful ways by paying attention to the relevant material, organizing it into a coherent mental structure, and integrating it with their prior knowledge (Mayer, 1999).

Research on the use of educational video shows that videos attract visual learners in support of multimedia learning's cognitive theory (Eick \& King, 2012). The Cognitive Theory of Multimedia Learning is the idea that we have auditory and visual channels for information processing and memory building and that the active learning process is more successful when both auditory and visual channels are simultaneously stimulated, also known as the dual channel assumption (Moreno \& Mayer, 2002). According to Mayer and Moreno (2002:90), "the cognitive integration process is most likely to take place when the learner has corresponding pictorial and verbal representations in working memory at the same time." Multimedia learning has been shown to support the incorporation of YouTube videos into the instruction (Eick \& King, 2012). In addition, the use of YouTube has been found to capture the attention of students (Buzzetto-More, 2014; Duvenger \& Steffes, 2012; Greenberg \& Zanetis, 2012), to make learning more interesting (Buzzetto-More, 2013), and to improve the overall learning process (BuzzettoMore, 2013; Jones \& Graham, 2013; Tan \& Pearce, 2012). Figure 1 shows the Multimedia Cognitive Theory of Moreno and Mayer.

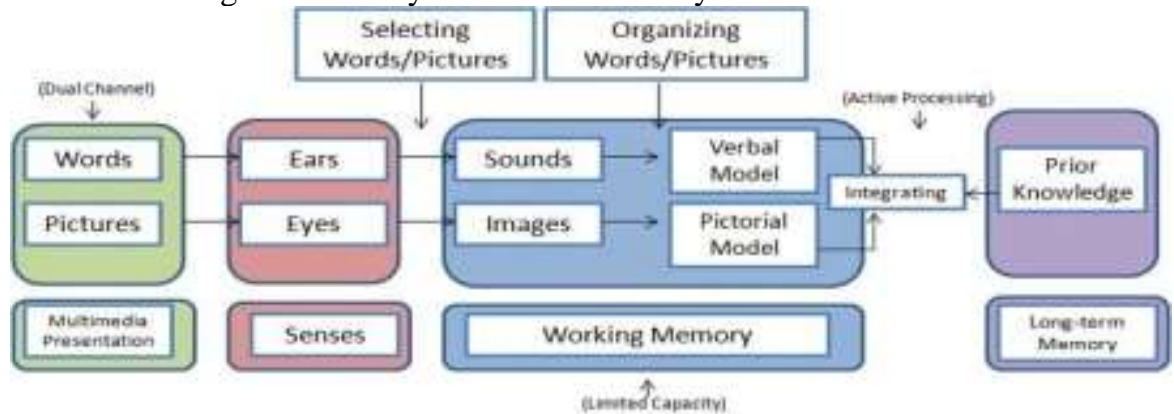

Figure 1

Moreno and Mayer's Cognitive Theory of Multimedia. Source: Moreno \& Mayer (2002) 


\section{Technology Acceptance Model (TAM)}

The present research was based on the TAM due to its prominence as a framework for measuring user-acceptance of a system (Zhou, Zhao, Kong, Campy, Qu \& Wang, 2019). Al-Gahtani (2016) posited that the TAM has received dedicated attention from notable scholar in the information systems field. I was therefore deemed appropriate for the present research to adapt and propose a modified version of the original TAM by Davis (1989).

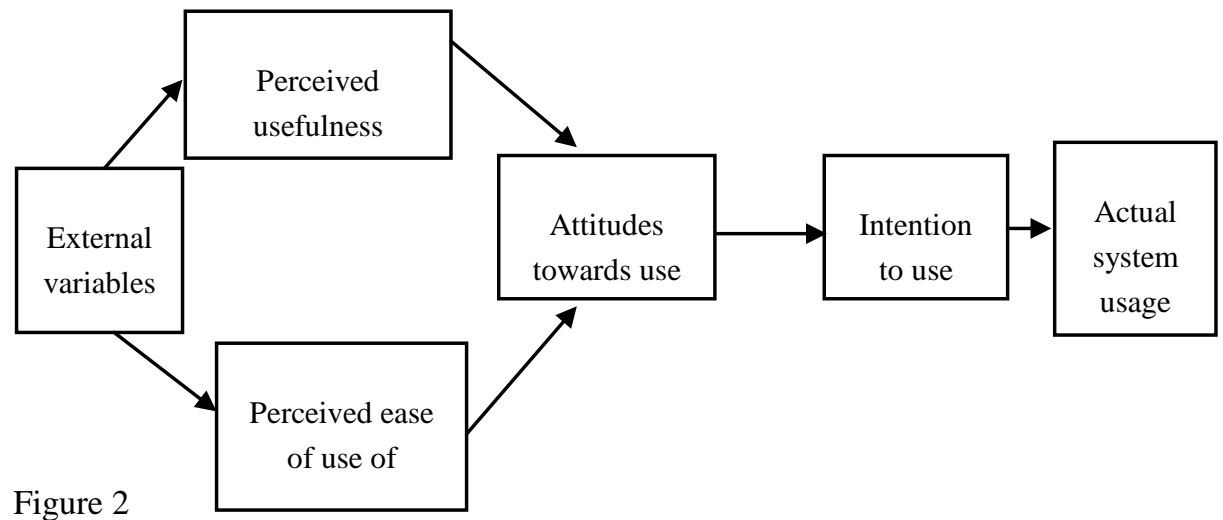

The Technology Acceptance Model. Source: Davis (1989) Technology Acceptance Model

The following research conceptual model is a modification of the technology.

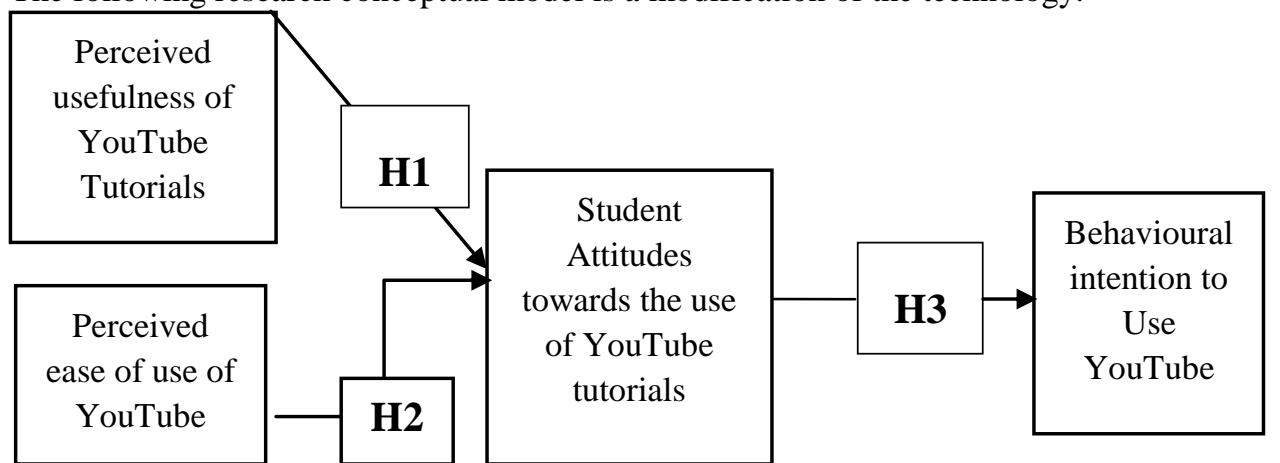

Figure 3

Modified YouTube learning Technology Acceptance Model

\section{Hypotheses Development}

\section{Perceived usefulness and attitudes towards use of YouTube}

Weng, Yang, Ho Su (2018) investigated the effects of the information technology (IT) environment on perceived usefulness, perceived ease of use and attitude towards multimedia use, and the relevance and influence of these attitudes on behavioural. They 
established that the intention to use multimedia teaching material for school teachers in Chiayi Country consequently, it can be hypothesized from the above-mentioned statements that:

H1: Perceived usefulness has a positive impact on attitudes towards use of YouTube amongst students

\section{Perceived ease of use and attitudes towards use of YouTube}

Perceived ease of use is the perception of how a technology is easy to use (Venkatesh, 2000; Yang \& Wang, 2019). It is assumed that this "perceived ease of use" is related to perceived usefulness of technology, motivation to use the technology and the behavioural intention to use that technology. Cheung and Vogel (2013) implied in their research that customer attitudes towards the use of technology will be directly influenced in a positive way by the ease of using a technology. A study by Burton-Jones and Hubona (2005) also revealed that perceived user-friendliness is a major determinant of a technology attitude.

In their study of what motivates individual online users to share their videos on YouTube, Yang, Hsu and Tan, (2010) results showed that perceived ease of use is an important determinant of the intention to use YouTube. Prior studies on technology in education that adopted the TAM have postulated that perceived ease of using technology directly influences attitudes towards the use of that technology (Chuchu \& Ndoro, 2019; Teo, 2009). From the above-mentioned elucidations, therefore, it can be assumed that:

$\mathrm{H} 2$ : Perceived ease of use has a positive impact on attitudes towards use of YouTube amongst students

\section{Attitudes towards use of YouTube and behavioural intentions to use YouTube}

Attitude as a cause of intention has been recognized (Suki \& Ramayah, 2010). In the study by Kim, Park \& Morrison (2008), attitude had a significant effect on behavioral intention and a moderately strong relationship, suggesting that individuals were more likely to use a technology if they felt positive about it. Alkhudaydi (2018) discovered that behavioral intention to use YouTube influences attitudes towards using YouTube. Consequently, this study suggests the following hypothesis:

H3: Attitudes towards use of YouTube has a positive impact on behavioural intentions of students to use YouTube

\section{LITERATURE REVIEW}

The rapid development of Internet technologies has encouraged an ever-so developing engagement with a 'making and doing' culture for creativity (Zhou \& Purushothaman, 2015). The Internet provides an ideal platform for hosting learning resources, including videos (Schaper, Ehlers, Dilly, Crowther \& Baillie, 2014). This has led to Academic institutions are progressively integrating new information and communication technologies (ICTs) in their educational systems (e.g. e-learning platforms, tablet PCs 
and instant messaging software) Blasco-Arcas, Buil, Hernandez-Ortega, \& Sese, 2013; Dündar \& Akçayir, 2014; Orús, Barlés, Belanche, Casaló, Fraj \& Gurrea, 2016).

\section{YouTube as an Educational Tool}

According to (Jackman, 2019). YouTube is one of the new e-resources that can be used in contemporary tertiary education pedagogy. In addition, YouTube, considered to be the most widely used view hosting website, is also seen as a prominent contemporary eresources with numerous benefits in the university classroom (Jackman, 2019). The research context for the present study was set within the a South African institution of higher learning and in other countries such as the United Sates it has already been established that YouTube videos are commonly used for teaching and learning (Smith, 2011; Schaper et al., 2014). YouTube videos can be a valuable source of content to supplement existing case teaching materials in health management and policy (Green, Aziz, Joseph, Ravanam, Shahab \& Straus, 2018). The relevance and use of YouTube in teaching and learning was cited by Dreon and Dietrich (2009) who pointed out positive reactions from teachers after viewing YouTube as motivation for utilising the videostreaming in an educational manner. One unique feature of YouTube is that two types of users can be clearly identified: the viewers and the content creators (de Bérail, Guillon \& Bungener, 2019).

Students who utilise YouTube tutorials could also be classified as content creators and users since some students upload the content for sharing purposes and other view for learning purposes. It has been found that social media fosters social learning in effective ways such that it can substitute traditional modes of instruction (Buzzetto-More, 2012; Buzzetto-More, 2014). The learning approach of traditional lecture-centred classrooms are being challenged by active learning hybrid programs such as YouTube (Hund \& Getrich, 2015. YouTube videos widely considered as easy to share with faculty in other fields and at other institution (Topps, Helmer \& Ellaway, 2013) making them useful for learning purposes. Ferrer, Belvís, \& Pamies (2011) established in their research that students from less affluent social background who had not previously received exposure to ICT devises such as tablet PCs did not perform in class as well as students who had received prior exposure to ICT. This then re-enforces the relevance and importance of modern communications in the learning environment.

\section{YouTube in Academia}

Recent advances in modern technology have created a surplus of electronic devices and e-platforms that are available to teachers at all levels (Jackman, 2019). The use of YouTube in academia has received great attention primarily in the medical academic field as indicated by literature (Clifton \& Mann, 2011; Green, et al., 2018; Schaper et al., 2014). Su and Kuo (2010) argued that YouTube is frequently used by university students and posting information literacy videos on YouTube increases visibility but does not easily achieve a comparable accomplishment of an extensive and wellstructured tutorial. Numerous librarians not only build information literacy tutorials on their library websites, but also post instructional short films on video sharing sites for easy access and high visibility (Su \& Kuo, 2010). 


\section{METHOD}

The study was quantitative in nature were the research design involved use of the survey method in-line with (Cakir \& Solak, 2015) to obtain data. In selection of data 381 students from a university in Johannesburg, South Africa were chosen through nonprobability sampling as participants of the study. Sample size determination was based on the Raosoft ${ }^{\circledR}$ sample size calculator which recommends a sample of 377 for an estimated population of 20000 (Raosoft, 2018). The calculator assumes that the data is normally distributed, response rate is at least $50 \%$, margin of error is at $5 \%$ and the confidence level is 95\%. The students were students spread across six academic departments, economics, marketing, information systems, insurance and risk, finance and management. The measurement instrument was based on a five point-Likert scale where perceived ease of use and were adapted from Adams et al., (1992). As for attitudes items were taken Chin (1998) and behavioural intention was adapted from Wong et al., (2013). The data was analysed through SPSS 25 and AMOS 25 for descriptive results and hypothesis testing respectively. Structural equation modeling was conducting in a 2-step approach starting with confirmatory factor analysis which was later-on followed by path modeling. Confirmatory factor analysis is a multivariate method for testing measurement models of the relationship between a set of observed variables and a hypothesised set of latent variables (Easterby, Thorpe, \& Jackson, 2012). While on the other hand, path modeling is a method used for analysing the causal relationship between the variables (Niemczyk, 2014). The results of the path modeling are presented in figure 3 .

\section{FINDINGS}

The sample's profile characteristics are presented in this section. The respective departments of the students, use of YouTube for tutorials and years of exposure to YouTube are all provided for the sample.

Table 1

Department

\begin{tabular}{llllll}
\hline \multicolumn{1}{l}{ Department } & Frequency & Percent & $\begin{array}{l}\text { Valid } \\
\text { Percent }\end{array}$ & $\begin{array}{l}\text { Cumulative } \\
\text { Percent }\end{array}$ \\
\hline \multirow{5}{*}{ Valid } & Economics & 35 & $9,3 \%$ & 9,3 & 9,3 \\
\cline { 2 - 6 } & Marketing & 26 & $6,9 \%$ & 6,9 & 16,2 \\
\cline { 2 - 6 } & Finance & 65 & $17,2 \%$ & 17,2 & 33,4 \\
\cline { 2 - 6 } & $\begin{array}{l}\text { Information } \\
\text { systems }\end{array}$ & 139 & $36,9 \%$ & 36,9 & 70,3 \\
\cline { 2 - 6 } & Insurance \& risk & 76 & $20,2 \%$ & 20,2 & 90,5 \\
\cline { 2 - 6 } & Management & 36 & $9,5 \%$ & 9,5 & 100,0 \\
\hline
\end{tabular}

It can be observed in the table above that in table 1 above most of the students that participated were information systems students as indicated by the $36,9 \%$. 
Table 2

Educational Level of Students

\begin{tabular}{llllll}
\hline \multicolumn{2}{l}{ Educational Level } & & & & \\
\hline \multirow{3}{*}{ Valid } & & Frequency & Percent & Valid Percent & Cumulative Percent \\
\cline { 2 - 6 } & First year & 103 & $27,3 \%$ & 27,3 & 27,3 \\
\cline { 2 - 6 } & Second year & 77 & $20,4 \%$ & 20,4 & 47,7 \\
\cline { 2 - 6 } & Third year & 93 & $24,7 \%$ & 24,7 & 72,4 \\
\cline { 2 - 6 } & Honour's & 91 & $24,1 \%$ & 24,1 & 96,6 \\
\cline { 2 - 6 } & Master's & 13 & $3,4 \%$ & 3,4 & 100,0 \\
\cline { 2 - 6 } & Total & 377 & $100,0 \%$ & 100,0 & \\
\hline
\end{tabular}

Table 2 reveals that students at first and second year represented most of the participants while the master's students were the least represented group as indicated by only accounting for $3,4 \%$ of the total sample. The following table (table 3 ) illustrates the profile of students' use of YouTube for educational tutorials.

Table 3

Years of Exposure to YouTube Years of Exposure to YouTube

\begin{tabular}{llllll}
\multicolumn{2}{l}{ Years of Exposure to YouTube } & Frequency & Percent & Valid Percent & Cumulative Percent \\
\hline \multirow{4}{*}{ Valid } & & 1 & 0,3 & 0,3 & 0,3 \\
\cline { 2 - 6 } & 1 Year & 7 & 1,9 & 1,9 & 2,1 \\
\cline { 2 - 6 } & 2 Years & 117 & 31,0 & 31,0 & 33,2 \\
\cline { 2 - 6 } & 3 Years & 173 & 45,9 & 45,9 & 79,0 \\
\cline { 2 - 6 } & 4 Years & 79 & 21,0 & 21,0 & 100,0 \\
\cline { 2 - 6 } & 5 Years & 377 & 100,0 & 100,0 & \\
\hline
\end{tabular}

It is revealed in the table above that most of the students had at least 4 years of exposure to YouTube. This actually accounted for about two thirds of the entire sample. It could therefore be inferred that there is a possibility that some of the student had experience with YouTube before even attending university.

Table 4

YouTube use for Tutorials

Used YouTube for Tutorials

\begin{tabular}{llllll}
\hline & & Frequency & Percent & Valid Percent & Cumulative Percent \\
\hline \multirow{3}{*}{ Valid } & Yes & 307 & 81,4 & 81,4 & 81,4 \\
\cline { 2 - 6 } & No & 70 & 18,6 & 18,6 & 100,0 \\
\cline { 2 - 6 } & Total & 377 & 100,0 & 100,0 & \\
\hline
\end{tabular}

It can be observed in the table above that more than $80 \%$ of all participants have used YouTube tutorials for educational purposes. This was significantly more than the $19 \%$ that stated that they had not used YouTube tutorial for learning. It is evident that YouTube as an educational platform was very popular at the institution. The following table presents the number of years that the students had in terms of experience with and exposure to YouTube. The model fit indicators are presented in table 5 in the following section.

Table 5

Model fit Indicators

\begin{tabular}{lllllllll}
\hline Model fit criteria & CMIN//DF & GFI & CFI & IFI & NFI & RFI & TLI & RMSEA \\
\hline Indicator value & 2,522 & 0,926 & 0,979 & 0,980 & 0,967 & 0,956 & 0,973 & 0,007 \\
\hline
\end{tabular}


CFA Model: Confirmatory factor analysis model; CMIN/DF: Chi-square; GFI: Goodness of fit index; NFI: Normed Fit index; RFI; Relative Fit Index; IFI: Incremental Fit Index; TLI: Tucker Lewis Index; CFI: Comparative Fit Index. RMSEA: Root Measure Standard Error Approximation

The measurement model produced a ratio of chi-squared value over degree-of-freedom of 2.522 which is acceptable as it falls below the recommended 3 recommended (Ullman, 2001). Other model fit indices that included the GFI, CFI, IFI, NFI, RFI and TLI were $0.926,0.979,0.980,0.967,0.956$ and 0.973 respectively. All these model fit measures were above the recommended threshold of 0.9. The RMSEA was 0.043 which fell below the recommended threshold of 0.08 (Hooper, Coughlan \& Mullen, 2008). Figure 4 in the following section illustrates the confirmatory factor analysis model for the study.

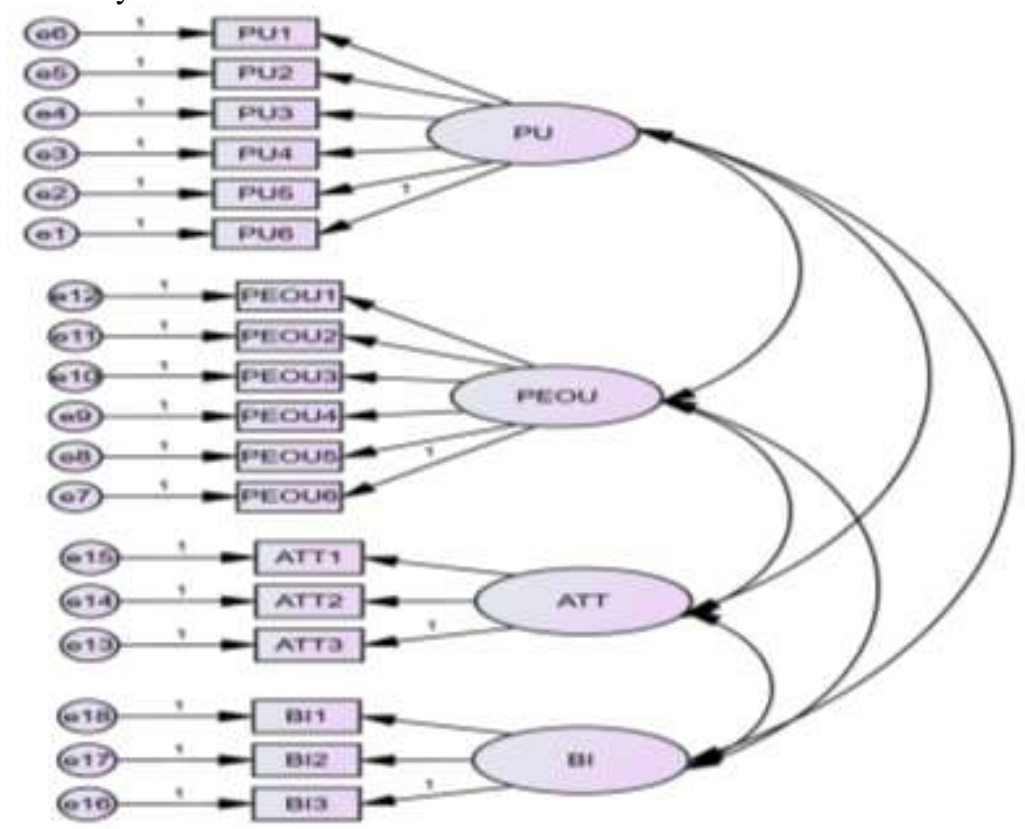

Figure 4

Confirmatory Factor Analysis Model

Key: PU: Perceived usefulness, PEOU: Perceived ease of use, ATT: Attitudes towards use of YouTube: BI: Behavioural intentions to use YouTube

Table 6

Descriptive, Reliability and Validity Results

\begin{tabular}{llllll}
\hline Construct & Mean & Std & (A) Alpha & Cr & Ave \\
\hline Perceived usefulness & 3,928 & 0,731 & 0,937 & 0,941 & 0,734 \\
\hline Perceived ease of use & 3,966 & 0,745 & 0,892 & 0,934 & 0,590 \\
\hline Attitudes towards using YouTube & 3,914 & 0,753 & 0,818 & 0,779 & 0,541 \\
\hline Behavioural intentions towards YouTube & 4,002 & 0,747 & 0,816 & 0,829 & 0,620
\end{tabular}

Key: STD: Standard deviation, ( $\alpha$ ) Alpha: Cronbach's alpha, CR: Composite reliability, AVE: Average variance extracted 
The descriptive, reliability and validity results are presented in the table above. The section that follows discusses these results as well as the model fit for the research. Cronbach's alpha coefficients were above 0.8 while the composite reliability values ranged from 0.816 to 0.937 . Furthermore, it was observed that most of the AVE values ranged from 0.541 to 0.620 . The measurement model produced a ratio of chi-squared value over degrees of-freedom was is acceptable as it fall below 2 as recommended by Tabachnick and Fidell (2007). Other model fit indices that included the GFI, CFI, IFI, NFI, RFI and TLI exceed the required 0.9 as suggested by Hooper, Coughlan and Mullen (2008). All these model fit measures were above the required value of 0.9. The RMSEA below 0.08 to meet the criteria proposed by (Hooper et al., 2008). The following section illustrates the structural model for the research after hypotheses testing. The structural model is presented in figure 5 below.

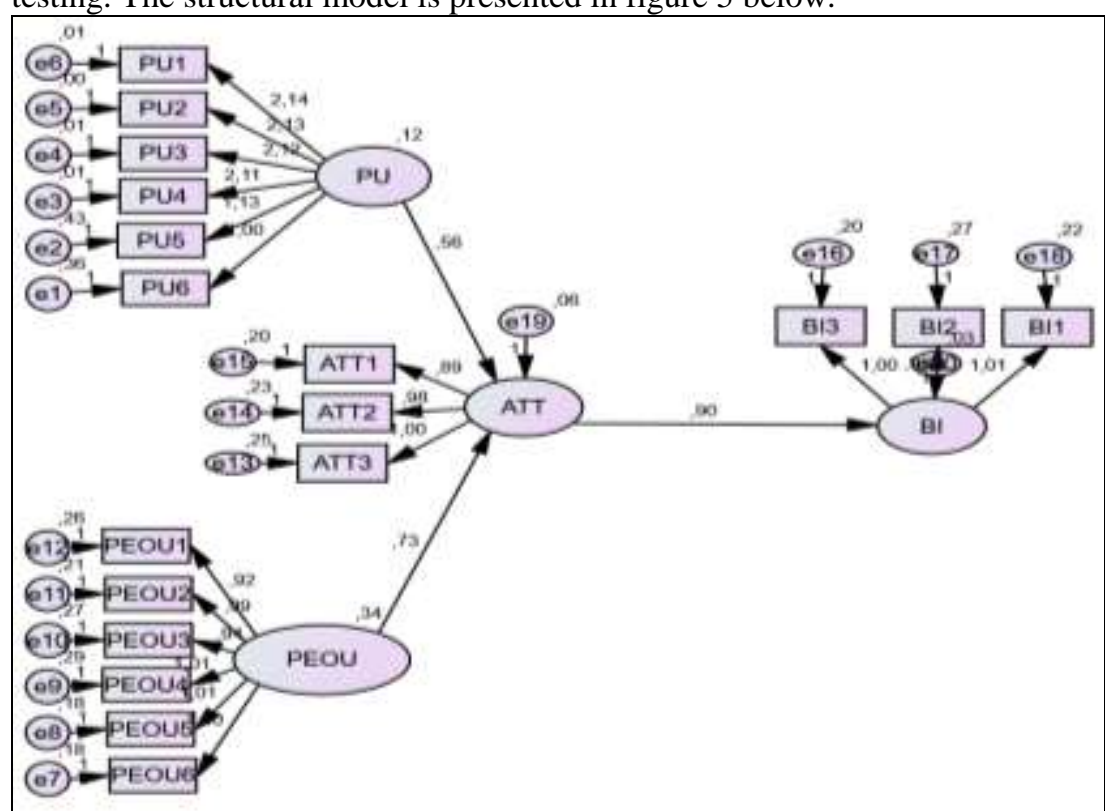

Figure 5

Structural Model

Source: Author's own work

Key: PU: Perceived usefulness, PEOU: Perceived ease of use, ATT: Attitudes towards use of YouTube: BI: Behavioural intentions to use YouTube

Table 7

Results of Hypothesis Testing

\begin{tabular}{lccc}
\hline Hypothesis Relationship & Estimate & P-Value & Outcome \\
\hline PU \& ATT & 0.56 & $* * *$ & Significant and supported \\
\hline PEOU \& ATT & 0.73 & $* * *$ & Significant and supported \\
\hline ATT \& BI & 0.90 & $* * *$ & Significant and supported \\
\hline$* * *=P<0.01$ level of significance. & &
\end{tabular}




\section{DISCUSSION}

In table 7 the findings from hypothesis testing are presented. According to the results perceived usefulness of YouTube for academic tutorials is directly and significantly associated with student attitudes towards the use of YouTube tutorials. This relationship had an estimate of 0.56 . The results obtained in this study are line with the findings of Scherer, Siddiq and Tondeur (2019) and Teo (2009) who suggested that perceived usefulness of technology does indeed influence attitudes towards the use of that technology. However, as much as it was supported it was the weakest implying that students did not view perceived usefulness as a crucial factor in relation to other factors as far as YouTube use for educational purposes was concerned. The second hypothesis established that perceived ease of use influences attitudes towards the use of YouTube for tutorials. This suggested that if students viewed YouTube as an easy accessible platform to receive tutorials they would become more positively inclined to continue using it. This finding is in line with the findings of $\mathrm{Wu}$ and Chen (2017) who confirmed that perceived ease of use directly influence attitudes towards the use of technology which ultimately leads to intention to use that technology. Lastly, attitudes toward the use of YouTube impacted the behavioural intentions of students to actually use it. This implied that if student attitudes towards YouTube are positive their most likely to consider using it as a result of their behaviour being influenced positively. This finding is supported by Yang, Chye, Fern and Kang (2015) who postulated and established that attitudes towards directly influence the intention to use a technology. All hypotheses were deduced from the literature and are supported by prior research as presented above.

\section{IMPLICATIONS}

From the results of this research, numerous implications arose. These include theoretical and practical implications. Firstly, it has been established theoretically that perceived usefulness of YouTube and perceived ease of use of YouTube positively and significantly influences student attitudes towards the use of YouTube. It was also discovered that student attitudes towards the use of YouTube positively and significantly influences behavioural intention to Use YouTube. Therefore, for academics in the field of instruction and educational development these finding enhances their understanding of the relationship of the aforementioned variables. This offers practical implications for education institution administrators such as vice chancelors and principapls as they need to concentrate more on providing internet accessablity to students who would want to use facebook for learning and tutorials. In terms of policy, governments are urged to implement laws policies that enable the youtube platform to be regarded as a learning platform.

\section{Limitations and Future Research Opportunities}

Despite the germane insights offered by this study, this study has its limitations which lead to future research. Although this study fills a gap in the academia, it should be noted that this study only focused on one institution, within the Johannesburg 
metropolitan area of South Africa. Thus, the results obtain from the surveys done at the institution cannot be generalised and assumed to be true for the rest of South Africa.

Other institutions can however be taken into consideration in further research to find other insightful outcomes.

Further research could consider investigating the same platform and purpose but looking at the relationship between perceived usefulness and perceived of use. This could potentially impact the effect that attitudes have on student behaviour towards the use of YouTube for learning purposes. Furthermore, this research was conducted from a student perspective and the instructor's views were not presented. It would be interesting to conduct comparative empirical studies between finds of the same study from an instructor's perspective with those of this study.

This research was based on a quantitative approach. Hence, to obtain more robust results the study's quantitative characteristic may have prompted the disregard of more illuminating and extravagant information, which a qualitative methodology could have created had it been converged in the investigation. Nevertheless, using triangulation would erase the effects of common method bias. Other researchers might opt to use both questionnaires and interviews to strengthen the research. Moreover, comparative studies between the findings of this study and those obtained from other countries through metaanalyses should also be considered in the future. This could lead to other thoughtprovoking insights that were not captured in the present study.

\section{CONCLUSIONS}

This study sort-out to invest student perceptions towards the use of YouTube as a platform for learning through watching video tutorials. It could be concluded that the use of YouTube in a formal learning environment was positively received. Furthermore, most notably the relationship between the student attitudes towards the use of YouTube and behavioural intentions was significantly strong possibly suggesting that this eplatform is a success with student learning at tertiary level. The results support all the postulated hypotheses, and managerial implications of the findings, limitations of the study and suggested future research were discussed. This study contributes new knowledge to the existing body of education management, instruction and learning literature in the African setting - a research context that is often neglected by academics.

\section{Acknowledgements}

The authors would like to say a special thank you to the Editor and all the anonymous reviewers for their invaluable comments and feedback. The authors are also thankful to the students who responded to this study.

\section{REFERENCES}

Adams, D. A., Nelson, R. R., \& Todd, P. A. (1992). Perceived usefulness, ease of use, and usage of information technology: A replication. MIS quarterly, 227-247. 
Albahlal, F. S. (2019). The impact of YouTube on improving secondary school students' speaking skills: English language teachers' perspectives. Journal of Applied Linguistics and Language Research, 6(2), 1-17.

Al-Gahtani, S. S. (2016). Empirical investigation of e-learning acceptance and assimilation: A structural equation model. Applied Computing and Informatics, 12(1), 27-50.

Alimemaj, Z. (2010). YouTube, language learning and teaching techniques. The Magazine of Global English-Speaking Higher Education, 2(3), 10-12.

Alkhudaydi, (2018). Investigating factors that influence the use of You Tube in teaching biology in high schools in Saudi Arabia based on the technology acceptance model. Electronic comprehensive journal for education and science publications, 13, 1-10.

Almobarraz, A. (2018). Utilization of YouTube as an information resource to support university courses. The Electronic Library, 36(1), 71-81.

Baddeley, A. D. (1986). Working memory. Oxford, England: Oxford University Press

Balcikanli, C. (2010, January). Long live, YouTube: L2 stories about YouTube in language learning. In Annals of Language and Learning: Proceedings of the 2009 International Online Language Conference (IOLC 2009), Universal-Publishers.

Berk, R. A. (2009). Multimedia teaching with video clips: TV, movies, YouTube, and $\mathrm{mtv} U$ in the college classroom. International Journal of Technology in Teaching \& Learning, 5(1), 1-21

Blasco-Arcas, L., Buil, I., Hernandez-Ortega, B., \& Sese, F. J. (2013). Using clickers in class. The role of interactivity, active collaborative learning and engagement in learning performance. Computers \& Education, 62, 102-110

Burton-Jones, A., \& Hubona, G. S. (2005). Individual differences and usage behavior: revisiting a technology acceptance model assumption. ACM SIGMIS Database: The DATABASE for Advances in Information Systems, 36(2), 58-77.

Buzzetto-More, N. (2012). Social networking in undergraduate education. Interdisciplinary Journal of Information, Knowledge, and Management, 7, 63-90

Buzzetto-More, N. (2015). Student attitudes towards the integration of YouTube in online, hybrid, and web-assisted courses: An examination of the impact of course modality on perception. Journal of Online Learning and Teaching, 11(1), 55-73.

Buzzetto-More, N. A. (2014). An examination of undergraduate student's perceptions and predilections of the use of YouTube in the teaching and learning process. Interdisciplinary Journal of E-Learning and Learning Objects, 10(1), 17-32.

Cakır, R., \& Solak, E. (2015). Attitude of Turkish EFL learners towards e-Learning through tam model. Procedia-Social and Behavioral Sciences, 176, 596-601. 
Camm, C. F., Russell, E., Xu, A. J., \& Rajappan, K. (2018). Does YouTube provide high-quality resources for patient education on atrial fibrillation ablation? International Journal of Cardiology, 272, 189-193.

Cheung, R., \& Vogel, D. (2013). Predicting user acceptance of collaborative technologies: An extension of the technology acceptance model for e-learning. Computers \& Education, 63, 160-175.

Chin, W. W. (1998). The partial least squares approach to structural equation modeling. Modern Methods for Business Research, 295(2), 295-336.

Chuchu, T., \& Ndoro, T. (2019). An examination of the determinants of the adoption of mobile applications as learning tools for higher education students. International Journal of Interactive Mobile Technology, 13(3), 53-67

Clark, J. M., \& Paivio, A. (1991). Dual coding theory and education. Educational Psychology Review, 3, 149-210.

Clifton, A., \& Mann, C. (2011). Can YouTube enhance student nurse learning? Nurse Education Today, 31(4), 311-313.

de Bérail, P., Guillon, M., \& Bungener, C. (2019). The relations between YouTube addiction, social anxiety and parasocial relationships with YouTubers: A moderatedmediation model based on a cognitive-behavioral framework. Computers in Human Behavior, 99, 190-204.

Donoker, F. (2011). Assessment of learner acceptance and satisfaction with video-based instructional materials for teaching practical skills at a distance. International Review of Research in Open and Distance Learning . 12(5), 74-92

Dreon Jr, O., \& Dietrich, N. I. (2009). Turning lemons into lemonade: Teaching assistive technology through wikis and embedded video. TechTrends, 53(1), 78-80

Duncan, I., Yarwood-Ross, L., \& Haigh, C. (2013). YouTube as a source of clinical skills education. Nurse Education Today, 33(12), 1576-1580.

Dündar, H., \& Akçayir, M. (2014). Implementing tablet PCs in schools: students' attitudes and opinions. Computers in Human Behavior, 32, 40-46

Duvenger, P., \& Steffes, E. (2012). Using YouTube videos as a primer to affect academic content retention. Working Together Works: Partnering for Progress 2012 CUMU National Conference, (pp. 51-66).

Easterby, M., Thorpe, R., \& Jackson, P. (2012). Management research. Thousand Oaks, CA: Sage.

Eick, C., \& King, T. (2012). Nonscience majors' perceptions on the use of YouTube video to support learning in an integrated science lecture. Journal of College Science Teaching, 42(1), 26-30. 
Ferrer, F., Belvís, E., \& Pamies, J. (2011). Tablet PCs, academic results and educational inequalities. Computers \& Education, 56(1), 280-288

Flannelly, L.T., Flannelly, K.J. \& Jankowski, K.R., 2014, 'Independent, dependent, and other variables in healthcare and chaplaincy research'. Journal of Health Care Chaplaincy, 20(4), 161-170.

Green, J. C., Aziz, T., Joseph, J., Ravanam, A., Shahab, S., \& Straus, L. (2018). YouTube enhanced case teaching in health management and policy. Health Professions Education, 4(1), 48-58.

Greenberg, A., \& Zanetis, J. (2012). The impact of broadcast and streaming video in education. Report Commissioned by Cisco Systems Inc. to Wainhouse Research L.L.C. Retrieved from http://www.cisco.com/web/strategy/docs/education/ciscovideowp.p.

Gunzler, D. D., \& Morris, N. (2015). A tutorial on structural equation modeling for analysis of overlapping symptoms in co-occurring conditions using MPlus. Statistics in Medicine, 34(24), 3246-3280.

Hooper, D., Coughlan, J., \& Mullen, M. (2008). Structural equation modelling: Guidelines for determining model fit. Electronic Journal of Business Research Methods, 6(1), 53-60

Hund, L., \& Getrich, C. (2015). A pilot study of short computing video tutorials in a graduate public health biostatistics course. Journal of Statistics Education, 23(2), 1-16

Jackman, W. M. (2019). YouTube usage in the university classroom: An argument for its pedagogical benefits. International Journal of Emerging Technologies in Learning, 14(9), 157-166.

Jones, B., \& Graham, C. (2002). Practices and tools in online course delivery. In K. Yefim (Ed.), Learning management systems and instructional design: Metrics, standards, and applications (pp. 288- 302). Hershey, PA: I.G.I. Global.

Jones, T., \& Cuthrell, K. (2011). YouTube: Educational potentials and pitfalls. Computers in the Schools, 28(1), 75-85.

Jordaan, M., \& Jordaan, A. J. J. (2017). Using YouTube as a reflection tool for a service-learning module. Proceedings of the 4th Biennial Conference of the South African Society for Engineering Education, Cape Town, South Africa.

June, S., Yaacob, A., \& Kheng, Y. K. (2014). Assessing the use of YouTube videos and interactive activities as a critical thinking stimulator for tertiary students: An action research. International Education Studies, 7(8), 56-67.

Kelly, M., McGrath, M., \& Cannon, G. (2009). A multi-method study to determine the effectiveness of, and student attitudes to, online instructional videos for teaching clinical nursing skills. Nurse Education Today, 29(3), 292-300.

Kim, D. Y., Park, J., \& Morrison, A. M. (2008). A model of traveller acceptance of mobile technology. International Journal of Tourism Research, 10(5), 393-407. 
Las

Vegas,

NV.

http://sloanconsortium.org/sites/default/files/et4online_2012_programbook_lowres.pdf.

Mayer, R. E. (1999). Research-based principles for the design of instructional messages: The case of multimedia explanations. Document Design, 1, 7-20.

Mayer, R. E. (2003). Elements of a science of e-learning. Journal of Educational Computing Research, 29(3), 297-313.

Mayer, R. E. (2009). Multimedia learning. New York: Cambridge University Press.

Mayer, R. E., \& Moreno, R. (1998). A split-attention effect in multimedia learning: Evidence for dual processing systems in working memory. Journal of Educational Psychology, 90, 312-320.

Moreno, M., \& Mayer, R. (2002). Animation as an aid to multimedia learning. Educational Technology Review, 14(1), 87-90.

Mullen, R., \& Wedwick, L. (2008). Avoiding the digital abyss: Getting started in the classroom with YouTube, digital stories, and blogs. The Clearing House: A Journal of Educational Strategies, Issues and Ideas, 82(2), 66-69.

Niemczyk, A. (2014). The application of path modelling in the analysis of consumer behaviour in the cultural tourism market. Economics \& Sociology, 7(1), 204.

Paivio, A. (1986). Mental representations: A dual coding approach. Oxford, England: Oxford University Press.

Paras, J. (2001). Crisis in mathematics education. Student failure: challenges and possibilities. South African Journal of Higher Education, 15(3), 66-73.

Raosoft (2018) Sample size calculator. Retrieved from http://www.raosoft.com/samplesize.html.

Revoir, R. (2012). Can YouTube help students learn about business ethics? SLOAN $-C$ 5th Annual International Symposium Emerging Technologies for Online Learning.

Roodt, S., \& Peier, D. (2013). Using YouTube in the classroom for the net generation of students. In Proceedings of the Informing Science and Information Technology Education Conference (pp. 473-488). Informing Science Institute.

Roodt, S., de Villiers, C., Johnston, K., Ophoff, J., \& Peier, D. (2014). YouTube as an academic tool for ICT lecturers. Proceedings of the e-Skills for Knowledge Production and Innovation Conference, Cape Town, South Africa, 389-399. Retrieved from http://proceedings.e-skillsconference.org/2014/e-skills389-399Roodt763.pdf.

Russell, B., \& Purcell, J., (2009). Online research essentials: Designing and implementing research studies. Hobokken, NJ: Wiley.

Schaper, E., Ehlers, J. P., Dilly, M., Crowther, E., \& Baillie, S. (2014). Using YouTube to share teaching resources. Journal of the American Veterinary Medical Association. 245(4), 372-373 
Scherer, R., Siddiq, F., \& Tondeur, J. (2019). The technology acceptance model (TAM): A meta-analytic structural equation modeling approach to explaining teachers' adoption of digital technology in education. Computers \& Education, 128, 13-35.

Sekaran, U. \& Bougie, R., (2016), Research methods for business: A skill building approach. New York, NY: Wiley.

Smith, H. M., (2011) Global connections via YouTube: Internet video as a teaching and learning tool. In N. Biamonte (Ed.), Pop-culture pedagogy in the music classroom: teaching tools from American Idol to YouTube. Lanham, Md: Scarecrow Press.

Snelson, C. (2010). Web-Based video for e-learning: Tapping into the YouTube phenomenon. In H. Yang, \& S. Yuen (Eds.), Collective intelligence and e-learning 2.0: Implications of web-based communities and networking (pp. 147-166). Hershey, PA.

Su, S. F., \& Kuo, J. (2010). Design and development of web-based information literacy tutorials. The Journal of Academic Librarianship, 36(4), 320-328.

Suki, N. M., \& Ramayah, T. (2010). User acceptance of the e-government services in Malaysia: structural equation modelling approach. Interdisciplinary Journal of Information, Knowledge, and Management, 5(1), 395-413.

Sweller, J. (1988). Cognitive load during problem solving: Effects on learning. Cognitive Science, 12, 257-285.

Sweller, J. (1994). Cognitive load theory, learning difficulty, and instructional design. Learning and Instruction, 4, 295-312.

Szeto, E., \& Cheng, A. Y. N. (2014). Exploring the usage of ICT and YouTube for teaching: A study of pre-service teachers in Hong Kong. The Asia-Pacific Education Researcher, 23(1), 53-59.

Tabachnick, B.G. \& Fidell, L.S. (2007), Using Multivariate Statistics. New York: Allyn and Bacon.

Tan, E., \& Pearce, N. (2012). Open education videos in the classroom: exploring the opportunities and barriers to the use of YouTube in teaching introductory sociology. Research in Learning Technology, 19, 128-137.

Teo, T. (2009). Modelling technology acceptance in education: A study of pre-service teachers. Computers \& Education, 52(2), 302-312.

Topps, D., Helmer, J., \& Ellaway, R. (2013). YouTube as a platform for publishing clinical skills training videos. Academic Medicine, 88(2), 192-197.

Venkatesh, V. (2000). Determinants of perceived ease of use: Integrating control, intrinsic motivation, and emotion into the technology acceptance model. Information Systems Research, 11, 342-365

Watkins, J., \& Wilkins, M. (2011). Using YouTube in the EFL classroom. Language Education in Asia, 2(1), 113-119. 
Weng, F., Yang, R. J., Ho, H. J., \& Su, H. M. (2018). A TAM-based study of the attitude towards use intention of multimedia among school teachers. Applied System Innovation, 1(3), 1-9.

Wong, K.-T., Osman, R.-B. T., Goh, P. S. C., \& Rahmat, M. K. (2013). Understanding student teachers' behavioural intention to use technology: technology acceptance model (TAM) validation and testing. International Journal of Instruction, 6(1), 89-104.

Wu, B., \& Chen, X. (2017). Continuance intention to use MOOCs: Integrating the technology acceptance model (TAM) and task technology fit (TTF) model. Computers in Human Behavior, 67, 221-232.

Yang, C., Hsu, Y. C., \& Tan, S. (2010). Predicting the determinants of users' intentions for using YouTube to share video: moderating gender effects. Cyberpsychology, Behavior, and Social Networking, 13(2), 141-152.

Yang, K. C., Chye, G. N. S., Fern, J. C. S., \& Kang, Y. (2015). Understanding the adoption of mobile commerce in Singapore with the technology acceptance model (TAM). In Assessing the different roles of marketing theory and practice in the jaws of economic uncertainty (pp. 211-215). Springer, Cham.

Yang, Y., \& Wang, X. (2019). Modeling the intention to use machine translation for student translators: An extension of Technology Acceptance Model. Computers \& Education, 133, 116-126

Zhou, C., \& Purushothaman, A. (2015). The need to foster creativity and digital inclusion among women users in developing context-addressing second order digital divide in online skills. International Journal of Emerging Technologies in Learning, 10(3), 69-74.

Zhou, M., Zhao, L., Kong, N., Campy, K. S., Qu, S., \& Wang, S. (2019). Factors influencing behaviour intentions to telehealth by Chinese elderly: An extended TAM model. International journal of medical informatics, 126, 118-127. 